\title{
Grinding Method for Increasing Specific Surface Area of Fluidized Bed Fly Ash
}

\author{
Chang Sung Lim and Ki Gang Lee $\mathbb{1}^{\dagger}$ \\ Department of Advanced Material Science and Engineering, Kyonggi University, Suwon 16227, Korea
}

(Received January 8, 2019; Received March 5, 2019; Accpted March 6, 2019)

\begin{abstract}
In this study, fly ash of a fluidized bed boiler produced in a power plant was stabilized by hydration and carbonation reaction. Then, each raw material was pulverized by two kinds of grinding equipment (Planetary mills and pot mills); the degree of grinding and the agglomeration behavior were observed. It was found that there were changes of specific surface area and particle size distribution according to grinding time. The surface of the raw material was observed using an optical microscope. As a result, agglomerates of about $75 \mu \mathrm{m}$ or more due to electrostatic phenomenon were formed as the grinding time became longer; it was confirmed that the crushing efficiency slightly increased with use of antistatic agent.
\end{abstract}

Key words : Grinding, Fluidized bed fly ash, Agglomeration, Hydration, Carbonation

\section{Introduction}

C onstruction waste is dominantly comprised of waste concrete, which has contributed to increasing environmental pollution due to illegal dumping as the previous method of simple landfills has begun to reach its limits. Not only that, recently growing interest in the lack of natural aggregates, conservation of national resources, and environmental conservation has brought recycled aggregates, derived from the reprocessing of waste concrete, to the forefront from an environmental and economic perspective. However, the usage of recycled aggregates is limited because of concerns regarding concrete strength and durability degradation, along with the occurrence of alkali-aggregate reactions due to cement paste existing in the recycled aggregate. In order to resolve such problems, the use of fly ash as admixture is actively being researched. ${ }^{1)}$

The fly ash produced in coal-fired power plants is used as an admixture to enhance the properties of concrete, including improving the concrete durability as well as concrete fracture reduction and long-term strength enhancement by reducing the hydration heat. As such, fly ash has recently been used widely both domestically and internationally. ${ }^{2)}$ Most construction sites still use ordinary Portland cement (OPC) and, as a result, the performance required for various structures is not attained and problems such as crack propagation and strength degradation have occurred due to excessive hydration heat from the use of large amounts of

\footnotetext{
Corresponding author: Ki Gang Lee

E-mail : gglee@kyonggi.ac.kr

Tel : +82-31-249-9762 Fax : +82-31-244-6300

ORCID

http://orcid.org/0000-0002-2053-5884
}

cement. ${ }^{3)}$ In an effort to resolve these problems, active research and development using fine fly ash and blast-furnace slag as admixtures are being carried out.

The combustion process of using coal in a thermal power plant to produce energy includes the pulverized coal combustion method and the circulating fluidized bed combustion method. The circulating fluidized bed combustion method has recently been a center of interest as a power generation technology because the combustion method exhibits excellent diversification of applied fuels, and economic feasibility and environmental friendliness of the facilities. Also, since the conventional desulfurization system is very costly, a fluidized bed boiler with a long bituminous coal combustion time can be used to perform desulfurization within the furnace and a circulating fluidized bed boiler is used for low combustion temperature and NOx generation minimization. However, the circulating fluidized bed combustion method carries out desulfurization in the furnace, so a large amount of $\mathrm{CaO}$ compounds is contained in the coal ash and the $\mathrm{SiO}_{2}$ content does not conform to the KS standard (KS L5405). When it is used as a concrete admixture, the free- $\mathrm{CaO}$ component that does not participate in the concrete hydration reaction induces critical problems regarding the concrete durability, expansion, weathering, and cracks, resulting in everything being landfilled and not being recycled. ${ }^{4)}$

In domestic and international studies, fly ash is mixed and then ground before usage. Especially, while there are a lot of cenospheres of spherical particle form in conventional pulverized coal ash so that fluidity is high, fluidized bed coal ash has almost no cenospheres and cannot satisfy the fluidity of KS L 5405; thus, the specific surface area (Blaine) has to be increased through pulverization. Fly ash is used by categorizing it by type according to fineness based on KS L 5405. ${ }^{5)}$ Chindaprasirt et $a l .^{6)}$ studied the overall strength 
improvement effect when increasing the basic Blaine value by using fly ash mixture as a concrete admixture. Additionally, the fineness of OPC was varied to investigate the hydration reaction properties and compressive strength. ${ }^{7,8)}$ In order to use fly ash in concrete, quality criteria like $\mathrm{SiO}_{2}$ content, fineness, density, moisture, ignition loss, flow ratio, and activity factor are selected for maintenance of KS L 5405. Among these KS quality criteria, fly ash types including type $1\left(4,500 \mathrm{~cm}^{2} / \mathrm{g}\right.$ and above), type $2\left(3,000 \mathrm{~cm}^{2} / \mathrm{g}\right.$ and above), type $3\left(2,500 \mathrm{~cm}^{2} / \mathrm{g}\right.$ and above), and type 4 (1,500 $\mathrm{cm}^{2} / \mathrm{g}$ and above) are classified based on the fineness as measured using an air permeability apparatus. Fineness is a factor that determines the quality of fly ash and is considered the most important criterion that determines whether a material can be utilized as a concrete additive. ${ }^{9)}$

In this study, literature review showed that factors of fly ash that affect the strength, including the particle size distribution, specific surface area, chemical composition, and mineral composition impact the pozzolanic reaction rate. ${ }^{10)}$ In order to recycle the fluidized bed coal ash as a concrete admixture, hydration and carbonation reactions were carried out to increase the Blaine value of the coal ash stabilized through hydration/carbonation of free $\mathrm{CaO}$; this was followed by planetary and ball milling to investigate the pulverization effect according to the pulverization equipment through fineness measurement and particle size distribution measurement, as well as the pulverization efficiency according to the particle size distribution variation during pulverization. Moreover, the pulverization efficiency with respect to time was studied by varying the pulverization duration. The agglomeration behavior due to static electricity of the fine powder raw material became a problem; so, in order to resolve the electrostatic agglomeration phenomenon between particles due to pulverization, the antistatic agent DEG was added to increase the pulverization efficiency of the fluidized bed coal ash and increase the Blaine value.

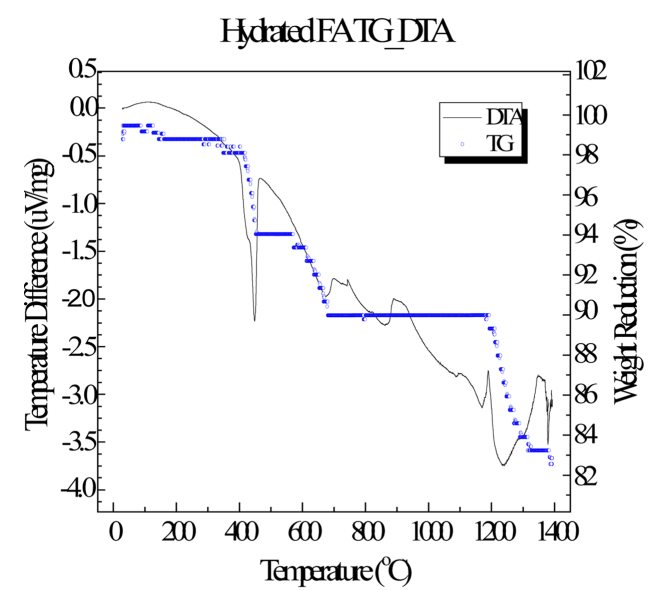

(a)

Fig. 1. TG/DTA measurement results (a) HFA, (b) CFA.
Table 1. Chemical Composition of Various Types of Fly Ash

\begin{tabular}{cccc}
\hline & $\begin{array}{c}\text { As-received } \\
\text { Fly Ash } \\
\text { (RFA) }\end{array}$ & $\begin{array}{c}\text { Hydrated } \\
\text { Fly Ash } \\
\text { (HFA) }\end{array}$ & $\begin{array}{c}\text { Carbonated } \\
\text { Fly Ash } \\
\text { (CFA) }\end{array}$ \\
\hline $\mathrm{SiO}_{2}$ & 24.73 & 24.37 & 21.17 \\
$\mathrm{Al}_{2} \mathrm{O}_{3}$ & 10.33 & 10.48 & 8.57 \\
$\mathrm{Fe}_{2} \mathrm{O}_{3}$ & 4.95 & 4.31 & 4.36 \\
$\mathrm{CaO}$ & 38.41 & 32.36 & 31.15 \\
$\mathrm{MgO}$ & 4.54 & 3.85 & 3.72 \\
$\mathrm{Na}_{2} \mathrm{O}$ & 4.03 & 3.28 & 2.64 \\
$\mathrm{~K}_{2} \mathrm{O}$ & 0.84 & 0.87 & 0.66 \\
$\mathrm{TiO}_{2}$ & 0.51 & 0.48 & 0.44 \\
$\mathrm{P}_{2} \mathrm{O}_{5}$ & 0.13 & 0.12 & 0.11 \\
$\mathrm{C}$ & 0.32 & 0.85 & 4.69 \\
$\mathrm{~S}$ & 10.15 & 9.05 & 10.5 \\
$\mathrm{Ig}$. Loss & 1.05 & 9.98 & 11.99 \\
$\mathrm{Total}$ & 100 & 100 & 100 \\
\hline
\end{tabular}

\section{Experimental Procedure}

\subsection{Raw Material Analysis}

RFA produced in the circulating fluidized bed combustion boiler was used as the raw material in this study. The chemical composition of the raw material was analyzed using XRF (ZSR-100e, Rigaku, Japan); the results are shown in Table 1. The $\mathrm{CaO}$ content and ignition loss of the fluidized bed coal ash were $38.35 \%$ and $1.05 \%$, respectively, where the ignition loss was very small. This result signified that a large amount of $\mathrm{Ca}$ exists in $\mathrm{CaO}$ form. Thus, there was a need to stabilize the free $\mathrm{CaO}$ for the stable use of this raw material as the concrete admixture; as such, stabilization was carried out through hydration and carbonation reactions. The hydrated fly ash was referred to as HFA and the carbonated fly ash was referred to as CFA. The ignition loss of the stabilized fly ash increased significantly at 9.98

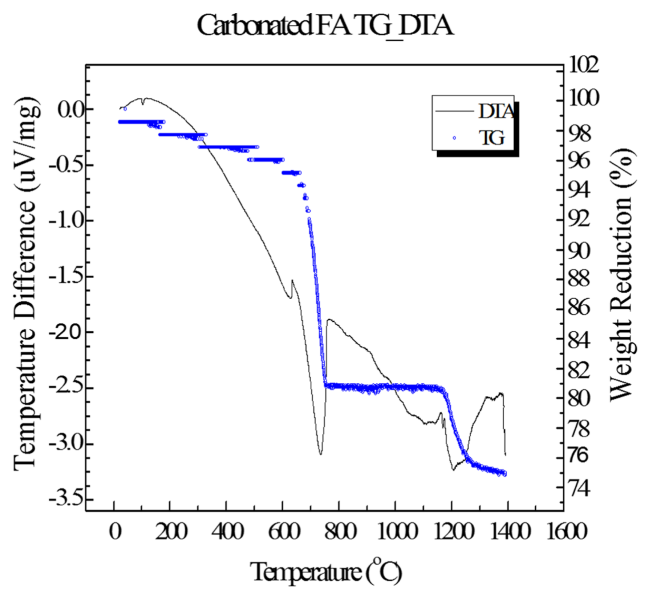

(b) 
wt\% and 11.99 wt\% for HFA and CFA, respectively. The increase in the ignition loss due to the dehydration and decarbonation reactions at high temperature during stabilization is a natural phenomenon. Fig. 1 shows the TG/DTA measurement results. For HFA, most of the mass loss occurred at around $400 \sim 500^{\circ} \mathrm{C}$; for the CFA, most of the mass loss occurred at around $700 \sim 800^{\circ} \mathrm{C}$. This result shows that the temperatures of crystallization water and decarbonation are different. Mass loss was greater for CFA because, stoichiometrically, the removal of $\mathrm{CO}_{2}$ results in greater mass loss than the removal of $\mathrm{H}_{2} \mathrm{O}$.

\subsection{Raw Material Pulverization and Analysis}

The pulverization of the raw materials was performed using a pot mill (PM-002, MonotaRO, Japan) and a planetary mill (PM 100, Retsch, Germany). The pot mill was a ball mill that is commonly used in ceramic processing and involves placing the raw material with a ball in a pot and pulverizing the material by uniaxial rotation. The planetary mill is a pulverization apparatus that is more advanced than the pot mill; in the planetary mill, a small pot is installed in a large, rotating cylindrical disk. The large cylindrical disk rotates while the pot also rotates on its own and this rotation method induces greater ball motion than that of the pot mill. Thus, the planetary mill has a shorter pulverization time than the pot mill. Here, porcelain was used as the material for the jar and media of the pot mill, while alumina was used for the planetary mill. By varying the pulverization time for each piece of equipment depending on the efficiency of its pulverization apparatus, particle size distribution and Blaine value were observed for the pot mill and planetary mill. For the pot mill, pulverization was carried out for 20,40 , and 60 minutes, while pulverization was carried out for $5,10,15$, and 20 minutes for the planetary mill.

Particle size analysis (Mastersizer 3000, Malvern, U.K) was conducted to analyze the particle size distribution and Blaine value. The analysis results were compared with the particle size distribution measurements obtained using a sieve. For the Blaine measurement, an air permeability apparatus (Auto Blaine tester, Hanil Lab. Tech, Korea) was used in accordance with KS L5106 ${ }^{10)}$ to compare the size of the raw material; ${ }^{11)}$ a Camscope (Dr. Campscope, Mikey, Korea) was used to observe the raw material and determine its agglomeration state.

In order to observe the electrostatic agglomeration phenomenon, the antistatic agent diethylene glycol (DEG) was used, added at a level of $0.01 \%$. Pulverization was carried out using the planetary mill in the same manner as explained earlier.

\section{Results and Discussion}

\subsection{Particle Size Distribution of the Starting Mate- rial}

Figure 2 shows the particle size distributions of the RFA,

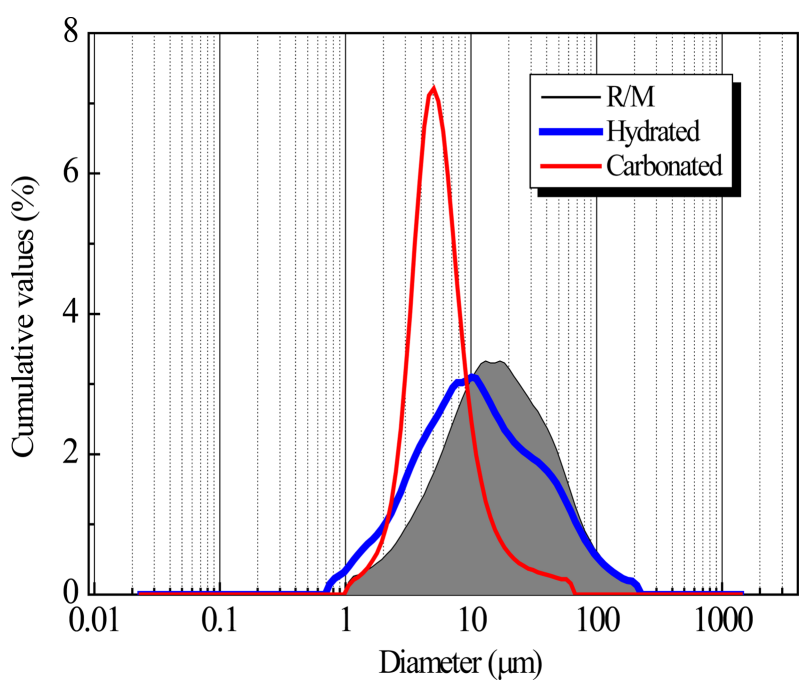

Fig. 2. Particle Size Distribution of Various Kinds of Fluidized Bed Fly Ash.

Table 2. Particle Size Distribution Obtain by Sieving Raw Materials

\begin{tabular}{|c|c|c|c|c|c|}
\hline & Sieve & & RFA & HFA & CFA \\
\hline \multicolumn{3}{|c|}{ Blaine $\left(\mathrm{cm}^{2} / \mathrm{g}\right)$} & 1,900 & 2,100 & 2,200 \\
\hline \multirow{4}{*}{$\begin{array}{c}\text { Particle } \\
\text { Size } \\
\text { Distribution }\end{array}$} & $0 \sim 45(\mu \mathrm{m})$ & & 28.4 & 7.3 & 5.6 \\
\hline & $45 \sim 75(\mu \mathrm{m})$ & \multirow{3}{*}{$\mathrm{wt}(\%)$} & 54.7 & 34.4 & 69.6 \\
\hline & $75 \sim 106(\mu \mathrm{m})$ & & 7.4 & 30.7 & 13.1 \\
\hline & $106 \sim(\mu \mathrm{m})$ & & 9.5 & 27.6 & 11.7 \\
\hline
\end{tabular}

HFA, and CFA. The RFA had an average particle size of approximately $15 \mu \mathrm{m}$, while the average particle sizes of the HFA and CFA were approximately $9 \mu \mathrm{m}$ and $5 \mu \mathrm{m}$, respectively. These results show that the free $\mathrm{CaO}$ of the RFA reacted with $\mathrm{Ca}(\mathrm{OH})_{2}$ for HFA and RFA divided due to the expansion stress to become finer particles. For CFA, there was further expansion as $\mathrm{Ca}(\mathrm{OH})_{2}$ reacted with $\mathrm{CaCO}_{3}$, so that additional division occurred to result in fine particles.

Table 2 shows the Blaine values and sieve particle size distributions for the starting materials. The Blaine value of RFA was found to be $1900 \mathrm{~cm}^{2} / \mathrm{g}$, falling short of $3000 \mathrm{~cm}^{2} / \mathrm{g}$. For HFA and CFA, although it was expected that they would have high specific surface areas as their average particle sizes were smaller than that of RFA, their Blaine values were not significantly different from that of RFA at $2100 \mathrm{~cm}^{2} / \mathrm{g}$ and $2200 \mathrm{~cm}^{2} / \mathrm{g}$, respectively.

\subsection{Particle Size Analysis}

Table 2 shows the particle size distributions analyzed through sieving of RFA, HFA, and CFA. Compared to RFA, HFA and CFA had fewer particles below $45 \mu \mathrm{m}$, while there were more particles of $45 \sim 106 \mu \mathrm{m}$. This result contrasted with the result of the particle size distribution measurement shown in Fig. 2. Generally, as the agglomeration of fine particles is reflected, measurement through sieving results in more larger particles being measured compared to 
PSA analysis, which is an instrumental analysis. Thus, this result was determined to be due to the agglomeration of particles, and the agglomeration phenomenon occurred for CFA with the smallest average particle size, so that the increase in particles of $45 \sim 75 \mu \mathrm{m}$ was largest. For HFA, there were increases in the $45 \sim 75 \mu \mathrm{m}$ and $75 \sim 106 \mu \mathrm{m}$ intervals. This result was thought to be due to the agglomeration of fine particles during drying in the hydration and carbonation processes; this phenomenon causes the particle size to increase more from agglomeration the finer the raw material is. So, this result revealed that an increase in the specific surface through pulverization was necessary for usage of this material as a concrete admixture.

\subsection{Pot Mill Pulverization}

In Fig. 3, it is difficult to observe significant changes in the specific surface area for the pulverization using the pot mill up to about 60 minutes. This result was thought to be due to the pulverization limit of the pot mill. For the pulverization time of 20 minutes, an increase of around $1000 \mathrm{~cm}^{2} / \mathrm{g}$ was observed for HFA when compared to before pulverization, while an increase of around $2000 \mathrm{~cm}^{2} / \mathrm{g}$ was observed for CFA. However, the change in specific surface area was not significant even when the pulverization time was extended to 60 minutes.

As can be observed in the particle size distribution shown in Fig. 4, the $50 \mu \mathrm{m}$ large particles decreased for HFA compared to F/A, while the particles of about $20 \mu \mathrm{m}$ increased as the pulverization progressed. For CFA, the particle size appeared to increase for the interval of around $10 \mu \mathrm{m}$; however, for both cases, there were no changes in the particle size below $1 \mu \mathrm{m}$, so it was determined that there was no impact on the specific surface area variation.

For the particle size distribution when using the pot mill for the same pulverization time, CFA exhibited an overall fine result compared to HFA and CFA had a higher efficiency for the same pulverization time. Also, looking at the above graph, the 20-minute pulverization case for CFA

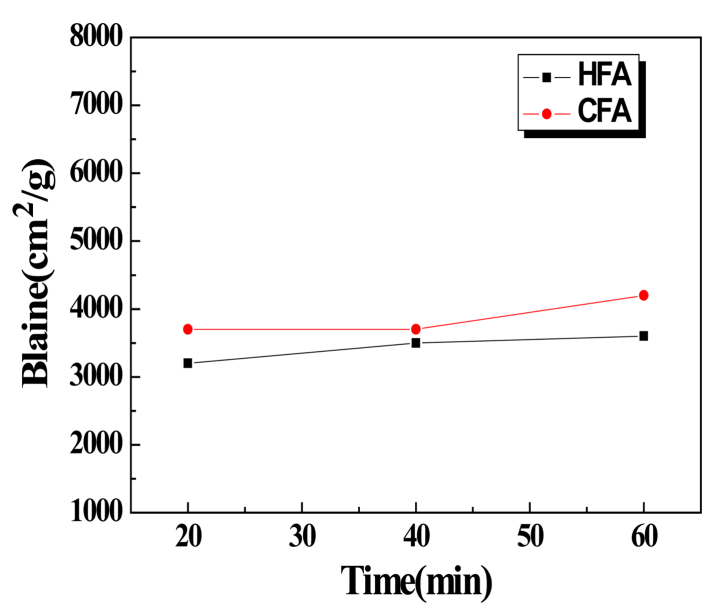

Fig. 3. Change in specific area of HFA and CFA pulverized by pot mill with time.

resulted in an observation of a higher ratio of fine particles compared to the pulverization time of 60 minutes. This result was thought to be due to the extended pulverization time inducing electrostatic agglomeration phenomenon of the pulverized particles and resulting in an increased size. When materials were pulverized through the pot mill method, increase of the specific surface area with respect to time was not apparent. Thus, additional pulverization experiments were conducted using the more advanced planetary mill method.

\subsection{Planetary Mill Pulverization}

Figure 5 shows the specific surface area measurement of the specimen pulverized using the planetary mill. Since the pulverization efficiency of the planetary mill is excellent compared to that of the pot mill, changes in the specific surface area of the powder were investigated by making the pulverization time relatively short. The specific surface area was measured and found to be around $4000 \sim 5000$ for CFA and $3500 \sim 4000$ for HFA. These values tended to increase

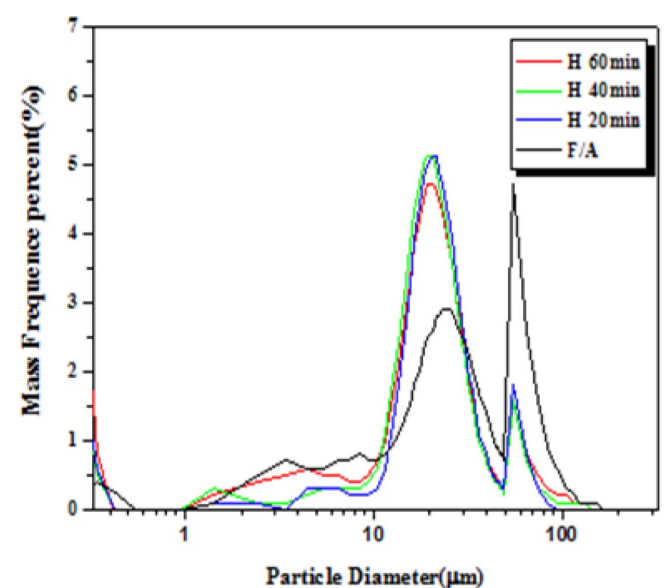

(a) HFA

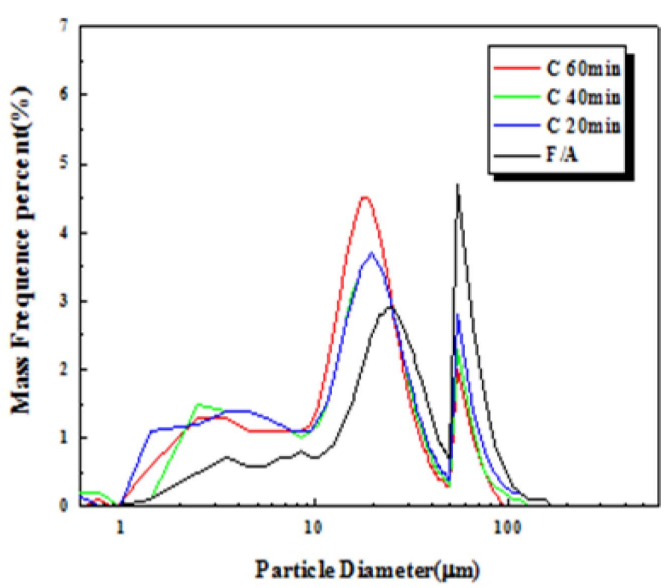

(B) CFA

Fig. 4. Particle size distribution of various kinds of fluidized bed fly ash. 


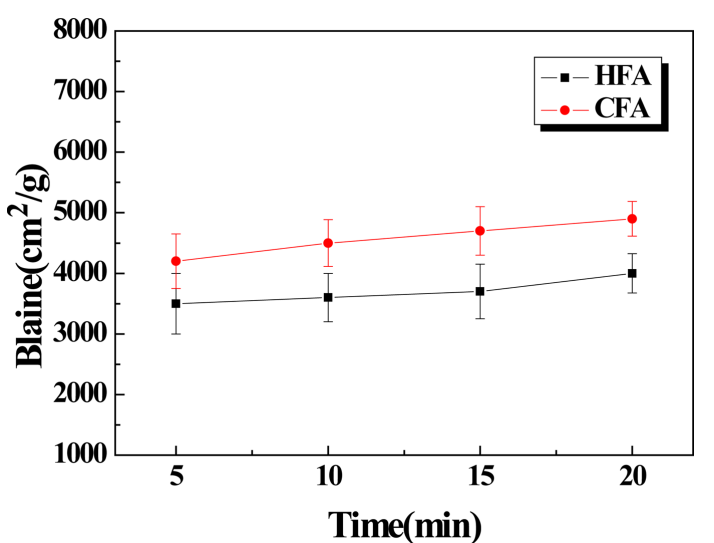

Fig. 5. Change in specific surface area of HFA and CFA pulverized by planetary mill with time.

gradually with time. Also, the specific surface area was found to be relatively higher than that of the specimens pulverized using the pot mill.

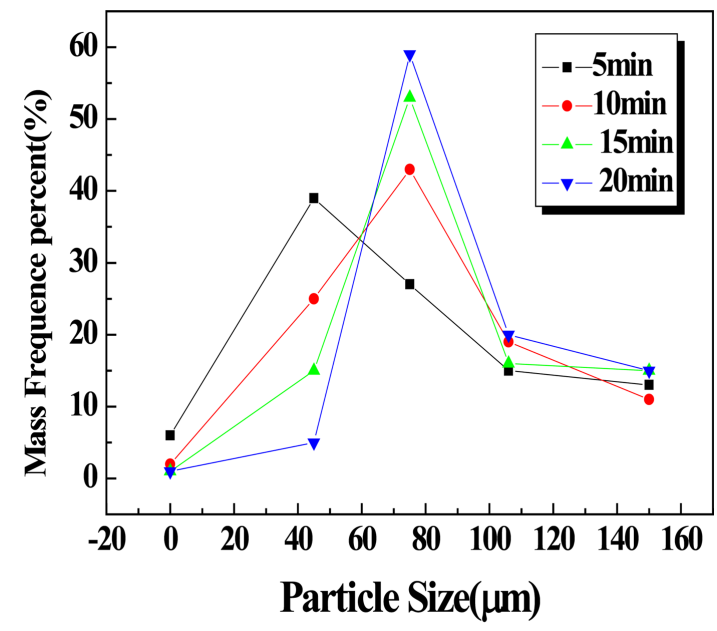

(a)

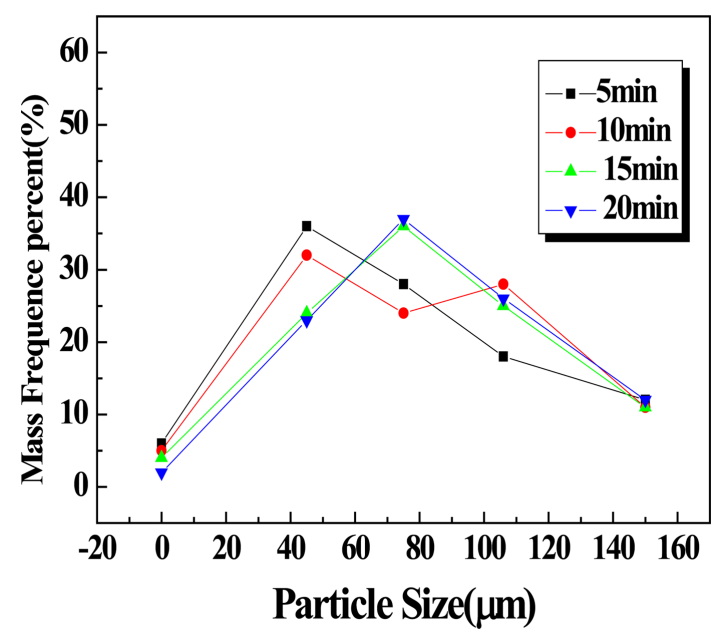

(b)

Fig. 6. Changes in particle size distribution due to pulverization time (a) HFA (b) CFA.
Figure 6 shows the results of the sieved pulverized raw materials. The measurement results reveal that, as the pulverization time increased, although there was an interval in which the overall particle size increased due to particle agglomeration, no decreases in the specific surface area were observed in the particle size distribution data.

Pulverization of the raw material at 5-minute intervals using the planetary mill resulted in an increase in the amount fine particles as the time increased and the refinement of the particles from pulverization continued. However, agglomeration of the raw material occurred in a specific interval, and this was thought to be due to the electrostatic agglomeration phenomenon of the raw material. In the case of HFA, the amount of aggregates in the $75 \mu \mathrm{m}$ interval increased as the pulverization time increased. In the case of CFA, the $45 \mu \mathrm{m}$ particle size distribution decreased as the pulverization time increased, while the particles above $75 \mu \mathrm{m}$ showed an increasing trend due to agglomeration. Due to the high specific surface area, it was difficult to accurately observe the particle size distribution through the

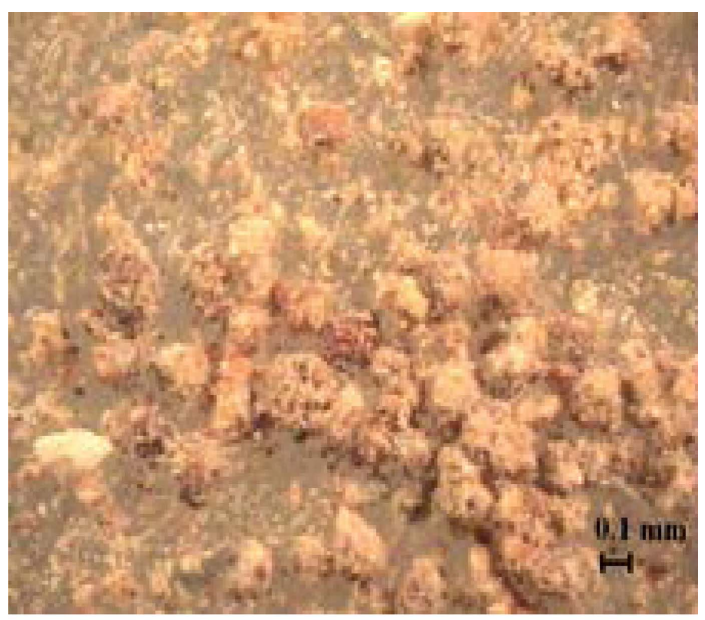

(a)

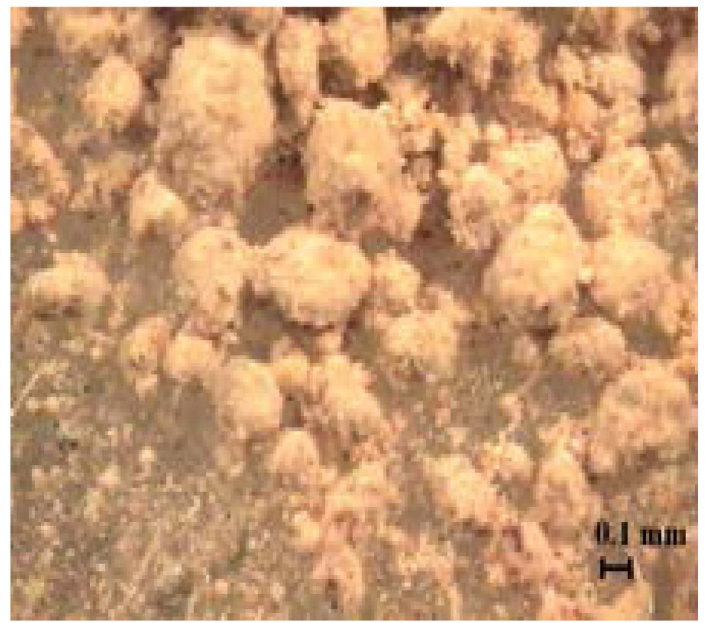

(b)

Fig. 7. Agglomerated section in Microstructure (a) HFA (b) CFA. 
sieve, despite the increase in fine particle content as the pulverization time increased. Despite the particle size being sufficient to pass through the sieve, the electrostatic agglomeration between particles caused the amount of specimen that could not pass through the sieve to increase, and so naturally the ratio of large particles increased. The agglomeration mainly occurred at the $75 \mu \mathrm{m}$ interval, so it was difficult to observe pulverization efficiency enhancement using the sieve method.

Figure 7 provides an image of the particles for each specimen, taken through an optical microscope. The observations show that carbonation particles were larger, which was thought to be due to the HFA particle agglomeration being weaker and leading to a rougher surface than was the case for CFA; as such, it was thought that in actuality CFA particles were smaller, making agglomeration occur more easily. In this way, the electrostatic agglomeration phenomenon of the particles occurred as the pulverization time increased; thus, the particle pulverization efficiency decreased.

Growth due to particle agglomeration did not exceed $75^{\circ} \mathrm{C}$ because when this size is exceeded, the agglomeration is pulverized again by the external force. Comparison of pulverization results for the pot mill and the planetary mill showed that the pulverization efficiency was higher for the planetary mill; also, for both pulverization methods, the pulverization efficiency decreased due to the electrostatic agglomeration phenomenon of particles when pulverization time increased.

\subsection{Antistatic Agent}

In the earlier experiment, it was found that the pulverization efficiency decreased because of particle agglomeration due to static electricity. So, an antistatic agent was added to prevent electrostatic agglomeration and the specific surface area was measured (Fig. 8). For both HFA and CFA, the specific surface area was found to significantly increase when the antistatic agent was used compared to when it was not used. The increase was greater for CFA and this

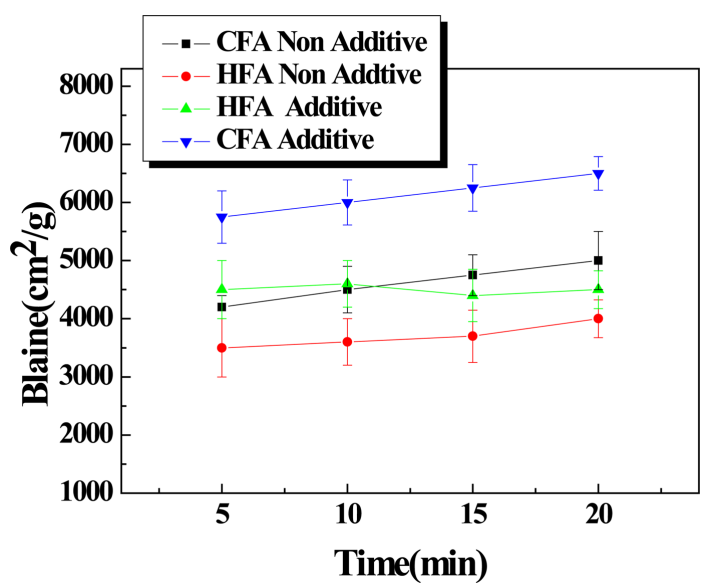

Fig. 8. Change of specific surface area according to pulverization with and without antistatic agent.

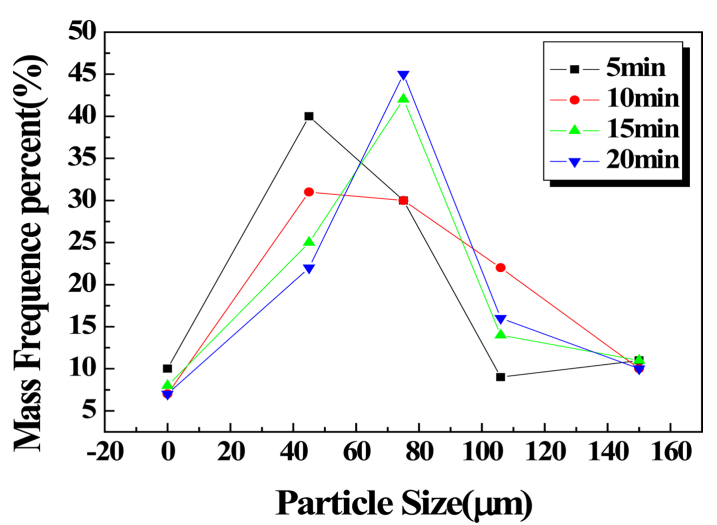

Fig. 9. Changes in particle size distribution due to pulverization time (HFA antistatic agent added).

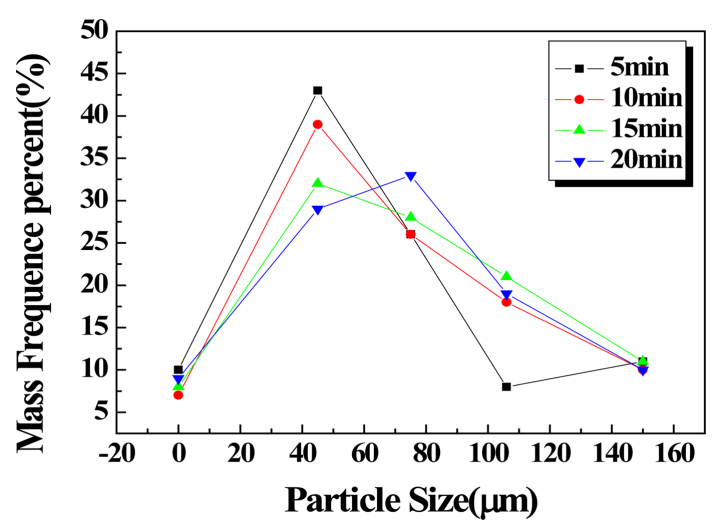

Fig. 10. Changes in particle size distribution due to pulverization time (CFA antistatic agent added).

was due to CFA being finer than HFA. Under the same conditions, the effect of the antistatic agent was more pronounced for the CFA specimen. Compared to CFA particles, HFA particles were larger and agglomeration occurred less; hence a greater effect was observed. Under the same conditions, specific surface area values increased by about $30 \%$ and $40 \%$ for HFA and CFA, respectively. For most intervals, the specific surface area value of the CFA raw material was higher than that of the HFA raw material and it was determined that the pulverization efficiency was higher for the CFA raw material than for that of HFA.

Figures 9 and 10 show the sieve experiment results for the specimen with the antistatic agent added. When the antistatic agent was used, the particle size distribution according to the pulverization time showed that when the same pulverization time was implemented, the antistatic effect for the agglomerated particles, compared to the case in which the antistatic agent was not added, was similar in that agglomeration occurred at $75 \mu \mathrm{m}$ for HFA; however, weight decreased from approximately $60 \%$ to $45 \%$, amount of fine particles increased, and the Blaine value accordingly increased. For CFA, large aggregates of $75 \mu \mathrm{m}$ decreased and small aggregates of $45 \mu \mathrm{m}$ increased slightly. 


\section{Conclusions}

The pulverization efficiency for various conditions and types of pulverization equipment and processing state of raw materials was observed using circulating fluidized bed coal ash; the following conclusions were obtained.

1) The planetary mill showed a higher pulverization efficiency than that of the pot mill and the particle size distribution of the planetary mill was more uniform.

2) As the pulverization time increased, agglomeration between particles tended to degrade the pulverization efficiency for the particle size of approximately $75 \mu \mathrm{m}$.

3) The particle size distribution and specific surface area measurement results showed that when the electrostatic agglomeration phenomenon was excluded, CFA had the highest specific surface area, followed by HFA and RFA. Also, the agglomeration phenomenon between particles appeared to increase as the particles became finer.

4) When the antistatic agent DEG was used to overcome the particle agglomeration phenomenon, an increase in the specific surface area of about $30 \sim 40 \%$ was observed and the pulverization efficiency increased, improving the reactivity of the fly ash.

\section{Acknowledgments}

This work was supported by the Kyonggi University Research Fund, 2016 (general research project).

\section{REFERENCES}

1. M. K. Lim, S.-D. Kim, S.-H. Lee, M. Y. Park, Y. D. Lee, and S. J. Jung, "A Study of the Strength and Durability Properties on Recycled Fine Aggregate Mortar and Blain of Blast Furance Slag,” Proc. Korea Concr. Inst., 2007 [5] 987-90 (2007).

2. K. G. Babu and G. S. Nageswara Rao, "Efficiency of Fly Ash in Concrete," Cem. Concr. Compos. 15 [4] 223-29 (1993).

3. C. G. Han, M. C. Han, and S. W. Kim, "Effect of the Fineness of the Cement made by Particle Size Screening Method on Mechanical Properties of the Concrete," J. Archit. Inst. Korea Struct. Constr., 23 [8] 123-30 (2007).

4. N. H. Mtarfi, Z. Rais, and M. Taleb "Effect of Clinker Free Lime and Cement Fineness on the Cement Physicochemical Properties." J. Mater. Environ. Sci., 8 [7] 2541-48 (2017).

5. KSL5405 "Fly ash" Korean Standards Association: Seoul, South Korea, 2018.

6. P. Chindaprasirt, C. Jaturapitakkul, and T. Sinsiri, "Effect of Fly Ash Fineness on Compressive Strength and Pore Size of Blended Cement Paste," Cem. Concr. Compos. 27 [4] 425-28 (2005).

7. Y. M. Zhang and T. J. Napier-Munn, "Effects of Particle Size Distribution, Surface Area and Chemical Composition on Portland Cement Strength," Powder Technol., 83 [3] 245-52 (1995).

8. N. Bouzoubaâ, M. H. Zhang, A. Bilodeau, and V. M. Malhotra, "The Effect of Grinding on the Physical Properties of Fly Ashes and a Portland Cement Clinker," Cem. Concr. Res., 27 [12] 1861-74 (1997).

9. R. Siddique, "Performance Characteristics of High-Volume Class F Fly Ash Concrete," Cem. Concr. Res., 34 [3] 487-93 (2004).

10. KSL5106 "Testing method for fineness of Portland cement by air permeability apparatus" Korean Standards Association: Seoul, Korea, 2009.

11. H. G. Ryu and J. K. Woo, "An Analysis on Concrete Properties with the Fineness of Waste Limestone," J. Korea Inst. Bulid. Constr., 7 [1] 85-90 (2007). 